\title{
Effects of propofol pretreatment on lung morphology and heme oxygenase-1 expression in oleic acid-induced acute lung injury in rats ${ }^{1}$
}

\author{
Zelong Tan', Huaizhou Wang", Jing Sun"', Mingsheng Li ${ }^{\mathrm{IV}}$
}

'Master, Department of Anesthesiology, Tai'an Central Hospital, Tai'an, Shandong, China. Conception, design, intellectual and scientific content of the study; manuscript writing; critical revision.

"Bachelor, Department of Anesthesiology, Yantai Stomatological Hospital, Yantai, Shandong, China. Scientific content of the study, acquisition of data.

"'Bachelor, Obstetrics and Gynecology, Tai'an Maternal and Child Health Hospital, Tai'an, Shandong, China. Acquisition of data.

IVMaster, Department of Anesthesiology, Tai'an Central Hospital, Tai'an, Shandong, China. Intellectual and scientific content of the study, critical revision.

\begin{abstract}
Purpose: To investigate the effects of propofol pretreatment on lung morphology and heme oxygenase-1 expression in oleic acid-induced acute lung injury in rats.

Methods: A total of 32 male Sprague-Dawley rats (250-300g) were randomly divided into the following four groups ( $n=8 /$ group): group $C$, group $O A$, group $O A+P R$, and group $O A+I X$ to compare related parameter changes.

Results: $\mathrm{PaO}_{2}, \mathrm{PCO}_{2}$, and $\mathrm{PaO}_{2} / \mathrm{FiO}_{2}$ were significantly different among the four treatment groups $(\mathrm{P}<0.05$ or $\mathrm{P}<0.01)$. Lung wet/dry weight ratio and $\mathrm{HO}-1$ protein expression also significantly differed among the groups $(P<0.01)$. Immunohistochemistry showed that the expression of $\mathrm{HO}-1$ in group $\mathrm{OA}+\mathrm{PR}$ was stronger than those in groups $\mathrm{OA}, \mathrm{OA}+\mathrm{IX}$, and $\mathrm{C}$. Light microscopy revealed that pathological changes in lung tissues in group $O A+P R$ were milder than those in group $\mathrm{OA}$ and group $\mathrm{OA}+\mathrm{IX}$. Electron microscopy showed that alveolar type II epithelial cell ultrastructure in group OA was relatively irregular with cell degeneration and disintegration and cytoplasmic lamellar bodies were vacuolized. Changes in group OA+PR were milder than those in group $\mathrm{OA}$; however, they were more severe in group $\mathrm{OA}+\mathrm{IX}$ than in group OA.
\end{abstract}

Conclusion: Propofol significantly increases the expression of $\mathrm{HO}-1$ in the lung tissueand prevents changes in lung morphology due to ALI in rats.

Key words: Propofol. Heme Oxygenase-1. Acute Lung Injury. Morphology. Rats. 


\section{- Introduction}

Acute lung injury (ALI) is a critical condition characterized by severe hypoxemia and respiratory distress. Conventional treatment measures do not effectively improve prognosis in such patients ${ }^{1}$. ALI is associated with innate immunity in ischemiareperfusion injury ${ }^{2}$, traumatic brain injury ${ }^{3}$, and septic shock ${ }^{4}$. Systemic inflammation is the fundamental cause of $\mathrm{ALI}^{5}$. Because the prevention of oxidative stress is reported to be beneficial in $A L I$, the expression of heme oxygenase-1 (HO-1) is also presumed to be associated with $\mathrm{ALI}^{6}$.

Propofol is a fat-soluble intravenous anesthetic that exerts good antioxidant effects; its lung-protective roles have also been verified $^{7-9}$. It can regulate innate immunity and the expression of proinflammatory signals in sepsis $^{10,11}$. It can also reduce the expression of toll-like receptor $2 / 4$ in sepsis ${ }^{12,13}$, attenuate the expression of NF-KB in sepsis ${ }^{14}$, and upregulate the expression ofHO- $1^{15}$. Although propofol is known to increase the expression of $\mathrm{HO}-1$ in $\mathrm{ALI}$, its effects on morphological changes in the lungs remain unexplored. This study investigated the impact of propofol on the histomorphology of the lung in oleic acid (OA)induced $\mathrm{ALI}$ in rats and explored its possible mechanisms of action, aiming to provide evidence for clinical treatment.

Propofol is a fat-soluble intravenous anesthetic that exerts good antioxidant effects; its lung-protective roles have also been verified $^{7-9}$. It can regulate innate immunity and the expression of proinflammatory signals in sepsis $^{10,11}$. It can also reduce the expression of toll-like receptor $2 / 4$ in sepsis ${ }^{12,13}$, attenuate the expression of NF-kB in sepsis ${ }^{14}$, and upregulate the expression ofHO- ${ }^{15}$. Although propofol is known to increase the expression of HO-1 in $A L I$, its effects on morphological changes in the lungs remain unexplored. This study investigated the impact of propofol on the histomorphology of the lung in oleic acid (OA)induced $A L I$ in rats and explored its possible mechanisms of action, aiming to provide evidence for clinical treatment.

\section{Methods}

The study was approved by the ethics committee of Tai'an Central Hospital, Tai'an, Shandong, China.

This study was carried out in strict accordance with the recommendations in the Guide for the Care and Use of Laboratory Animals of the National Institutes of Health ${ }^{16}$. The animal use protocol has been reviewed and approved by the Institutional Animal Care and Use Committee (IACUC) of Tai'an Central Hospital. All procedures were performed in accordance with the Declaration of Helsinki of the World Medical Association ${ }^{17}$.

\section{Sample collection}

Arterial blood $(0.5 \mathrm{ml})$ was withdrawn from the internal carotid artery, and dissolved gases in the blood were analyzed by a GEMpremierTM3000 blood gas analyzer (US Instrumentation Laboratory Company). After blood withdrawal, all rats were euthanized by cervical dislocation. Further, the left lung of each rat was isolated. The wet (W) and dry (D) weights (followed by $72 \mathrm{~h}$ drying to a constant weight at $80^{\circ} \mathrm{C}$ ) were noted, and the W/D weight ratio was calculated. The median lobe of the right lung of each rat was cut into a $0.3 \times 0.3 \times 0.5 \mathrm{~cm}$ portion and fixed in $10 \%$ neutral formalin $(\mathrm{pH} 7.2-7.4)$ for $24 \mathrm{~h}$ for immunohistochemical and HE staining. Histopathological findings were reported and double-checked by three different blinded pathologists.

\section{Immunohistochemistry results}

Immunohistochemistry was performed 
using a ready-to-use two-step (non-biotin) test kit. Rabbit anti-ratprimary antibodies, goat anti-rabbit secondary antibodies, and DAB chromogenic agent were purchased from Beijing ZSGB-Bio Origene Co., Ltd. A Leica DM1000 microscope (LeicaDFCT6.5.0 Switzerland Ltd.) was used to obtain images, which were analyzed for the integral optical density of HO-1 protein using the image-Pro Plus 6.0 optical analysis system. Each tissue section was sampled at five different fields and the average value was calculated.

Nine right lung lobes $(1 \times 1 \times 1 \mathrm{~mm})$ were also randomly sampled, followed by fixation in $2.5 \%$ glutaraldehyde. After rinsing twice with $0.1 \mathrm{M}$ PBS (10min/rinse), they were post-fixed with $1 \%$ osmic acid for $2 \mathrm{~h}$, treated with acetone gradient dehydration, and embedded by epoxy Resin 618. Ultrathin sections were prepared and stained stepwise with uranium dye and lead; the ultrastructure of the alveolar type II epithelial cells (AEC-II) was then observed using a Philips TECNAI10 electron microscope (the Netherlands Philips company).

Statistical analysis

All data analyses were performed using the SPSS13.0 statistical software; data are expressed as the mean \pm standard deviation. Inter groups differences were analyzed using one-way ANOVA followed by the LSD (when the variance was homogeneous) or Dunnett T3 (when the variance was non-homogeneous) post hoc test, with $\mathrm{P}<0.05$ considered as statistically significant.

\section{Results}

$\mathrm{PaO}_{2}, \mathrm{PCO}_{2}$ and $\mathrm{PaO}_{2} / \mathrm{FiO}_{2}$

$\mathrm{PaO}_{2}$ and $\mathrm{PaO}_{2} / \mathrm{FiO}_{2}$ in all $\mathrm{ALI}$ groups were significantly lower than those in group C $(\mathrm{P}<0.01)$; however, $\mathrm{PCO}_{2}$ was significantly higher $(\mathrm{P}<0.01) . \mathrm{PaO}_{2}$ and $\mathrm{PaO}_{2} / \mathrm{FiO}_{2}$ in group $\mathrm{OA}+\mathrm{PR}$ were significantly different from those in group $\mathrm{C}(\mathrm{P}>0.05) . \mathrm{PaO}_{2}$ and $\mathrm{PaO}_{2} / \mathrm{FiO}_{2}$ in group $\mathrm{OA}+\mathrm{PR}$ were significantly higher than those in group $\mathrm{OA}(\mathrm{P}<0.01)$; however, $\mathrm{PCO}_{2}$ was significantly lower $(\mathrm{P}<0.01) . \mathrm{PaO}_{2}$ and $\mathrm{PaO}_{2} /$ $\mathrm{FiO}_{2}$ in group $\mathrm{OA}+\mathrm{IX}$ were significantly lower than those in group $O A(P<0.01$ or $P<0.05)$ (Table 1).

Table 1 - Arterial blood gas analysis after injecting OA for $120 \min (\bar{x} \pm \mathrm{s}, \mathrm{n}=8)$.

\begin{tabular}{|c|c|c|c|}
\hline Group & $\mathrm{PaO}_{2}$ & $\mathrm{PCO}_{2}$ & $\mathrm{PaO}_{2} / \mathrm{FiO}_{2}$ \\
\hline C & $92.15 \pm 1.23$ & $39.65 \pm 1.77$ & $438.65 \pm 5.89$ \\
\hline $\mathrm{OA}$ & $56.15 \pm 4.36^{\boldsymbol{\Lambda}} \mathbf{\Delta}$ & $60.62 \pm 4.01^{\wedge \Lambda}$ & $266.08 \pm 20.56^{\Delta \Lambda}$ \\
\hline$O A+P R$ & $91.20 \pm 1.21^{\star \star}$ & $46.25 \pm 1.99^{\Delta \Delta \star \star}$ & $431.02 \pm 5.50 \star \star$ \\
\hline$O A+I X$ & $50.48 \pm 1.69 \Delta \Delta \star$ & $58.23 \pm 2.23^{\wedge \Lambda}$ & $239.78 \pm 8.01^{\Delta \Delta \star}$ \\
\hline
\end{tabular}

Compared with group $C_{,}{ }^{\wedge} \wedge P<0.01$; compared with group $\mathrm{OA},{ }^{\star \star} P<0.01,{ }^{\star} P<0.05$.

Lung $W / D$ weight ratio, lung injury score, and HO-1 protein expression

Lung W/D weight ratio, lung injury score, and HO-1 protein expression in all ALI groups were significantly higher than those in group $C(P<0.05$ or $P<0.01)$. Lung $W / D$ weight ratio and lung injury score in group $O A+P R$ were significantly lower than those in group OA $(\mathrm{P}<0.05$ or $\mathrm{P}<0.01)$; however, $\mathrm{HO}-1$ protein expression was significantly higher $(P<0.01)$. Group OA+IX exhibited significantly increased lung $W / D$ weight ratio and lung injury score $(\mathrm{P}<0.05)$ but significantly decreased $\mathrm{HO}-1$ protein expression $(\mathrm{P}<0.01)$ (Table 2$)$. 
Table 2 - Comparison of W/ D, lung injury score and IOD of HO-1 protein expression among different groups $(\bar{x} \pm \mathrm{s}, \mathrm{n}=8)$.

\begin{tabular}{llll}
\hline Group & W/D & lung injury score & HO-1 \\
\hline C & $3.66 \pm 0.05$ & $0.86 \pm 0.43$ & $3.55 \pm 0.14$ \\
OA & $5.79 \pm 0.20^{\star \Delta}$ & $2.65 \pm 0.55^{\star}$ & $4.77 \pm 0.04^{\star \Delta}$ \\
OA+PR & $4.76 \pm 0.15^{\Delta \star \star \star}$ & $1.53 \pm 0.51^{\star \star}$ & $5.15 \pm 0.06^{\Delta \star \star \star}$ \\
OA+IX & $5.96 \pm 0.16^{\Delta \star \star}$ & $2.84 \pm 0.53^{\star \star}$ & $4.28 \pm 0.12^{\star \Delta \star \star}$ \\
\hline
\end{tabular}

Compared with group $\mathrm{C}, \boldsymbol{\Delta} \Delta<0.01, \Delta P<0.05 ;$ compared with group $\mathrm{OA},{ }^{\star}{ }^{\star} P<0.01,{ }^{\star} P<0.05$.

Light microscopy of the lung tissue

The gross specimen images are shown in Figure 1. A clear lung structure was seen in group C; the alveolar septal capillaries were mildly expanded and congested, and the partial alveolar septa and bronchial stroma exhibited a small degree of lymphocyte infiltration. The lung tissue in group OA was damaged; the alveolar septal capillaries were markedly expanded and congested, scattered small focal bleeding was observed, and coagulated lung necrotic foci of different sizes were present.
The structure of the lung tissue in group $O A+P R$ was still clear; the alveolar septal capillaries were expanded and congested with only mild edema in the alveolar cavity. The structure of the lung tissue in group $\mathrm{OA}+\mathrm{IX}$ was damaged; the alveolar septal capillaries were markedly expanded and congested, the alveolar cavity was partially filled with edema fluid, extensive lymphocyte infiltration (with few neutrophils) was observed in the partial alveolar septum, and coagulated lung necrotic foci of different sizes were observed (Figure 1).

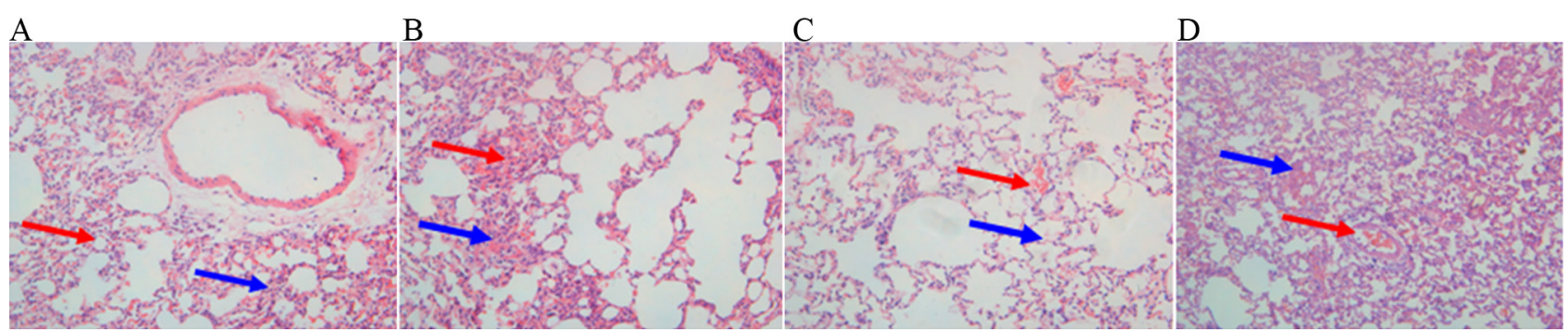

Figure 1 - A: Clear lung structure can be seen, the alveolar septal capillaries mildly expand and congest, and partial alveolar septum and bronchial stroma exhibit a small amount of lymphocyte infiltration; B: The structure of lung tissue is unclear, the alveolar septal capillaries expand and congest, together with scattered small focal bleeding and coagulated lung necrotic foci with different sizes; $\mathbf{C}$ : The structure of lung tissue is still clear, the alveolar septal capillaries expand and congest, and a small amount of edema fluid can be seen in the alveolar cavity; $\mathbf{D}$ : The structure of lung tissue is unclear, the alveolar septal capillaries exhibit high-degree expansion and congestion, partial alveolar cavity is filled with edema fluid, partial alveolar septum have the infiltration of a large number of lymphocytes and a small amount of neutrophils, together with coagulated lung necrotic foci with different sizes (HE staining x200).

HO-1 protein expression in the lung tissue

HO-1 protein in group OA+PR was strongly expressed in the bronchial cells, AECs, and alveolar macrophages; however, it was weakly expressed in groups $\mathrm{OA}, \mathrm{OA}+\mathrm{IX}$, and $\mathrm{C}$ (Figure 2). 


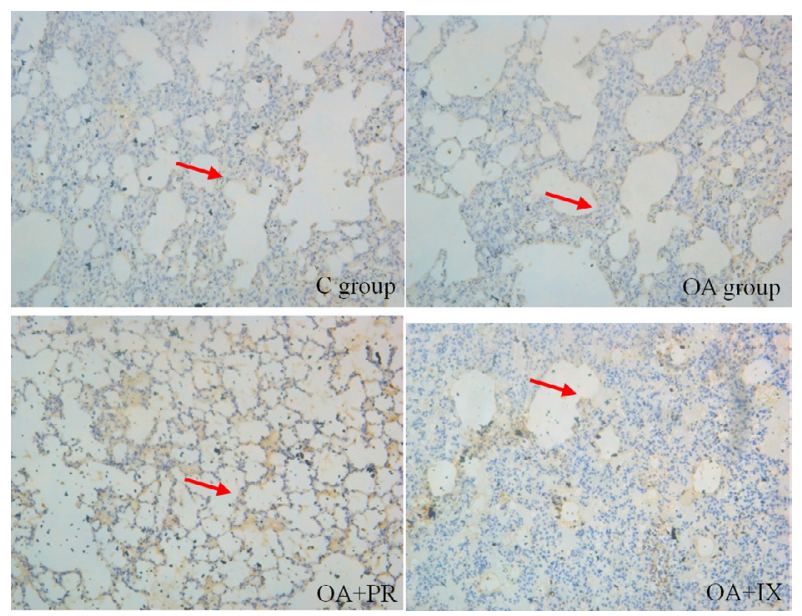

Figure 2 - The expression of HO-1 protein: OA+PR group was strong positive; $O A$ group and $O A+I X$ group, the expression was positive with $\mathrm{OA}+\mathrm{IX}$ group was weaker; the expression in $C$ group was weakly positive.

\section{AEC-II ultrastructure}

Electron microscopy revealed regular
AEC-II shape in group $C$; the cell surface was covered with microvilli of different lengths and thicknesses, the nuclei were conspicuous, and the cytoplasm contained various lamellar bodies in different numbers, sizes, and maturation stages. Group OA exhibited relatively irregular AEC-II shape, cell degeneration, and disintegration; the microvilli on the cell surface were reduced in number, and the cytoplasmic lamellar bodies were emptied (partially into the alveolar cavity). Group OA+PR exhibited relatively regular AEC-II shape, the microvilli were reduced in number, the nuclei were conspicuous, and the cytoplasm contained various lamellar bodies in different numbers and sizes. Group $\mathrm{OA}+\mathrm{IX}$ exhibited irregular AEC-II, cell degeneration, and disintegration; no microvilli were seen on the cell surface, and the cytoplasmic lamellar bodies were emptied and vacuolized (Figure 3).

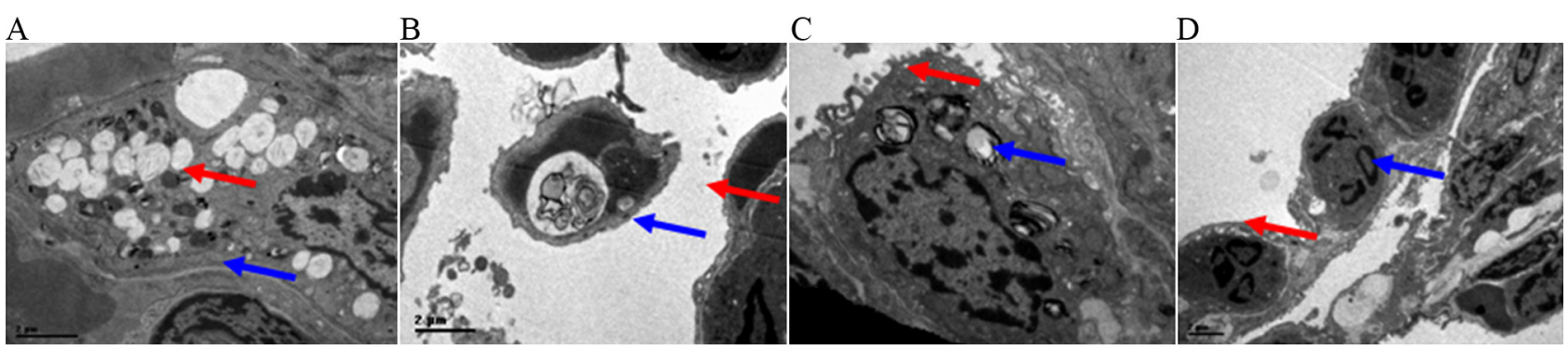

Figure 3 - A: Regular AEC-II shape in group C, the cell surface is covered with microvilli with different lengths and thickness, the nuclei are obvious, and the cytoplasm contains various lamellar bodies with different numbers and sizes, different maturation stages of which can also be seen; B: Group OA exhibits relatively irregular AEC-II shape, cell degeneration, or even disintegration; the microvilli on the cell surface are reduced, the cytoplasmic lamellar bodies are emptied (partially into alveolar cavity); C: Group OA+ PR exhibits relatively regular AT-II shape, the microvilli are reduced, the nuclei are obvious, the cytoplasm contains various lamellar bodies with different numbers and sizes; D: Group OA+IX exhibits irregular AEC-II, cell degeneration, or even disintegration, no microvillus can be seen on the cell surface, and the cytoplasmic lamellar bodies are emptied and vacuolized. Ultrastructure of AEC-II (red arrow: microvilli, blue arrow: lamellar bodies).

\section{- Discussion}

Results of this study show that $O A$ injection induced $\mathrm{ALI}$ in rats in a dose- and time-dependent manner ${ }^{18,19}$. OA-induced ALI presents an early phase of necrosis and microvascular thrombosis, followed by a repair phase with the proliferation of type II cells 
and fibrotic foci in subpleural areas ${ }^{20}$. The analysis of arterial blood gas $\mathrm{PaO}_{2}$ in group $\mathrm{OA}$ showed a progressive decline in respiratory capacity and significant cyanosis with the $\mathrm{PaO}_{2} / \mathrm{FiO}_{2}<300 \mathrm{mmHg}$. The lung $\mathrm{W} / \mathrm{D}$ weight ratio increased, and pathological damage was evident in the lung tissue, which also indicated alveolar space telangiectasia with scattered small focal bleeding without coagulation necrosis, alveolar collapse, and atrophy. These changes indicate ALI.

In this study, we evaluated the impact of propofol on OA-induced ALI in rats. Consistent with results of previous studies ${ }^{21}$, results of this study show that propofol can significantly reduce OA-induced ALI. We also found that HO-1 was strongly expressed in the propofol-pretreated lung tissue, which can significantly improve $\mathrm{PaO}_{2}$, significantly decrease lung W/D weight ratio, lung injury, and apoptosis of AT-II in OA rats. Zinc porphyrin IX also exhibited this effect, suggesting that $\mathrm{HO}-1$ is involved in the anti-apoptotic action of propofol. Propofol pretreatment significantly reducededema of the lung tissue ${ }^{21,22}$.

Previous studies have shown that propofol can inhibit inflammatory response by inhibiting reactive oxygen speciesregulated Akt/IKK $\beta / N F-k B$ signaling ${ }^{23}$ and reduce endotoxin-induced $A L^{24,25}$. Because the etiology of $A L I$ is complex, the protective effect of propofol on OA-induced ALI needs to be further investigated. $\mathrm{HO}-1$ plays a key role in $\mathrm{ALI}^{26,27}$. HO-1-based treatment strategies in $\mathrm{ALI}$ may be more meaningful, and drug discovery in this direction will increase our treatment options. Therefore, we aimed to identify the process by which propofol upregulates HO-1 expression to relieve OA-induced lung morphological changes in ALI.

$A L I$ is a dynamic pathophysiological process that injures the lung tissue. Although currently usedtreatment measures to control or eliminate causes of $A \mathrm{LI}$, including pulmonary protective ventilation, the rational application of antibiotics, liquid intake control, and continuous blood purification, exist, the prognosis of $\mathrm{ALI} /$ acute respiratory distresssyndrome (ALI/ ARDS) remains a challenge ${ }^{24}$. Therefore, there is a need to further investigate the occurrence and development mechanisms of ALI/ARDS and possible effective interventions. Based on previous studies ${ }^{21}$, we presumed that propofol has a protective effect on OAinduced ALI. This is the first study performed to compare the effects of propofol and zinc porphyrin IX pretreatment on ALI in terms of HO-1expression and lung histomorphology. We found that $\mathrm{PaO}_{2}$ and $\mathrm{PaO}_{2} / \mathrm{FiO}_{2}$ in group $\mathrm{OA}+\mathrm{PR}$ were significantly higher than those in group OA $(P<0.01)$; however, lung $W / D$ weight ratio and lung injury score were significantly lower $(\mathrm{P}<0.01$ and $\mathrm{P}<0.05$, respectively). The expression of HO-1 protein was significantly higher in group $O A+P R$ than in group $O A$ $(P<0.01)$, indicating that propofol induces the expression of HO-1. Zinc porphyrin IX (specific inhibitor of HO) was found to reduce HIF-1 $\alpha$ expression and inhibit hypoxia-mediated VEGF release and cell proliferation ${ }^{28}$ in group $\mathrm{OA}+\mathrm{IX}$. $\mathrm{PaO}_{2}$ and $\mathrm{PaO}_{2} / \mathrm{FiO}_{2}$ were significantly lower in group $\mathrm{OA}+\mathrm{IX}$ than in group $\mathrm{OA}(\mathrm{P}<0.05)$, whereas the lung $W / D$ weight ratio and lung injury score were significantly higher than in group $O A(P<0.01$ and $P<0.05$, respectively). The expression of HO-1 was significantly lower in group $\mathrm{OA}+\mathrm{IX}$ than in group $\mathrm{OA}(\mathrm{P}<0.01)$, which showed that $\mathrm{HO}-1$ expression was inhibited by zinc porphyrin IX. Consequently, the high expression of $\mathrm{HO}-1$ in group OA+PR was related to propofol, which is consistent with related reports ${ }^{25-29}$. This effect was confirmed by lung histomorphology analysis by light microscopy and AEC- II ultrastructure 
analysis by electron microscopy. The results of this study have high clinical importance in the diagnosis and treatment of ALI patients; however, because the results are mainly based on animal experiments, further human trials are necessary.

\section{Conclusion}

The pretreatment with propofol promotes the expression of $\mathrm{HO}-1$ in the lung tissue and significantly prevents changes in lung morphology due to ALI.

\section{References}

1. Neamu RF, Martin GS. Fluid management in acut respiratory distress syndrome. Curr Opin Crit Care.2013 Feb;19(1):24-30. doi: 10.1097/MCC.0b013e32835c285b.

2. Jing $H$, Yao J, Liu $X$, Fan $H$, Zhang $F$, Li Z, Tian $X$, Zhou Y. Fish-oil emulsion (omega-3 polyunsaturated fatty acids) attenuates acute lung injury induced by intestinal ischemia-reperfusion through Adenosine 5'-monophosphate-activated protein kinase-sirtuin1 pathway. J Surg Res. 2014 Mar;187(1):252-61. doi: 10.1016/j. jss.2013.10.009.

3. Song Z, Zhao X, Gao Y, Liu M, Hou M, Jin H, Cui Y. Recombinant human brain natriuretic peptide ameliorates traumainduced acute lung injury via inhibiting JAK/STAT signaling pathway in rats. J Trauma Acute Care Surg. 2015 May;78(5):980-7. doi: 10.1097/ TA.0000000000000602.

4. Lin WC, Chen CW, Huang YW, Chao L, Chao J, Lin YS, Lin CF. Kallistatin protects against sepsis-related acute lung injury via inhibiting inflammation and apoptosis. Sci Rep. 2015 Jul 22;5:12463. doi: 10.1038/srep12463.

5. Dzierba AL, Abel EE, Buckley MS, Lat I. A review of inhaled nitric oxide and aerosolized epoprostenol in acute lung injury or acute respiratory distress syndrome. Pharmacotherapy. 2014 Mar;34(3):279-90. PMID: 24734313.

6. Shiva S, Oh JY, Landar AL, Ulasova $E$,
Venkatraman A, Bailey SM, DarleyUsmar VM. Nitroxia: the pathological consequence of dysfunction in the nitric oxid-cytoehromecoxidase signaling pathway. Free Radic Biol Med. 2005 Feb 1;38(3):297-306. doi: 10.1016/j. freeradbiomed.2004.10.037.

7. Zhang L, Jin J, Yao J, Yue Z, Wei Y, Yang W, Fu S, Li W. Effects of propofol on excitatory and inhibitory amino acid neurotransmitter balance in rats with neurogenic pulmonary edema induced by subarachnoid hemorrhage. Neurocrit Care. 2016 Jun;24(3):459-71. doi: 10.1007/s12028015-0206-x.

8. Zhao W, Zhou S, Yao W, Gan X, Su G, Yuan $D$, Hei Z. Propofol prevents lung injury after intestinal ischemia-reperfusion by inhibiting the interaction between mast cell activation and oxidative stress. Life Sci. 2014 Jul 17;108(2):80-7. doi: 10.1016/j. Ifs.2014.05.009.

9. Yang $P$, Yang $N$, Zhang $X, X u X$. The significance and mechanism of propofol on treatment of ischemia reperfusion induced lung injury in rats. Cell Biochem Biophys. 2014 Dec;70(3):1527-32. doi: 10.1007/ s12013-014-0088-0.

10.Bao HG, Li S. Effects of propofol on the outcomes of rats with sepsis. J Surg Res. 2011 Jun 1;168(1):e111-5. doi: 10.1016/j. jss.2010.12.034.

11.Tang J, Hu JJ, Lu CH, Liang JN, Xiao JF, Liu YT, Lin CS, Qin ZS. Propofol inhibits lipopolysaccharide-induced tumor necrosis factor-alpha expression and myocardial depression through decreasing the generation of superoxide anion in cardiomyocytes. Oxid Med Cell Longev. 2014;2014:157376. doi: 10.1155/2014/157376.

12.Schläpfer $M$, Piegeler T, Dull RO, Schwartz DE, Mao M, Bonini MG, Z'Graggen BR, BeckSchimmer B, Minshall RD. Propofol increases morbidity and mortality in a rat model of sepsis. Crit Care. 2015 Feb 19;19:45. doi: 10.1186/s13054-015-0751-x.

13. Ma L, Wu XY, Zhang LH, Chen WM, Uchiyama A, Mashimo T, Fujino Y. Propofol exerts anti-inflammatory effects in rats with lipopolysaccharide-induced acute 
lung injury by inhibition of CD14 and TLR4 expression. Braz J Med Biol Res. 2013 Mar;46(3):299-305. PMID: 23532269.

14.Wang T, Wei XY, Liu B, Wang LJ, Jiang LH. Effects of propofol on lipopolysaccharideinduced expression and release of HMGB1 in macrophages. Braz J Med Biol Res. 2015 Apr;48(4):286-91. doi: 10.1590/1414431X20144222.

15.Liang C, Cang J, Wang $\mathrm{H}$, Xue Z. Propofol attenuates cerebral ischemia/reperfusion injury partially using heme oxygenase-1. J Neurosurg Anesthesiol. 2013 Jul;25(3):3116. doi: 10.1097/ANA.0b013e31828c6af5.

16. National Research Council (US) Committee for the Update of the Guide for the Care and Use of Laboratory Animals. Guide for the care and use of laboratory animals. Washington (DC): National Academies Press; 2011.

17.World Medical Association. World Medical Association Declaration of Helsinki. Ethical principles for medical research involving human subjects. Bull World Health Organ. 2001;79(4):373-4. PMID: 15835069.

18.Ulrich K, Stern M, Goddard ME, Williams J, Zhu J, Dewar A, Painter HA, Jeffery PK, Gill DR, Hyde SC, Geddes DM, Takata M, Alton EW. Keratinocyte growth factor therapy in murine oleic acid-induced acute lung injury. Am J Physiol Lung Cell Mol Physiol. 2005 Jun;288(6):L1179-92. doi: 10.1152/ ajplung.00450.2004.

19.Zhao LL, Hu GC, Zhu SS, Li JF, Liu GJ. Propofol pretreatment attenuates lipopolysaccharide-induced acutelung injury in rats by activating the phosphoinositide3-kinase/Akt pathway. Braz J Med Biol Res. 2014 Dec;47(12):1062-7. PMID: 25387673.

20.Lai JP, Bao S, Davis IC, Knoell DL. Inhibition of the phosphatase PTEN protects mice against oleic acid-induced acute lung injury. $\mathrm{Br} J$ Pharmacol. 2009 Jan;156(1):189-200. doi: 10.1111/j.1476-5381.2008.00020.x.

21.Gonçalves-de-Albuquerque CF, Silva AR, Burth P, Castro-Faria MV, Castro-FariaNeto HC. Acute respiratory distress syndrome: role of oleic acid-triggered lung injury and inflammation. Mediators Inflamm. 2015;2015:260465. doi:
10.1155/2015/260465.

22.Zhao LL, Hu GC, Zhu SS, Li JF, Liu GJ. Propofol pretreatmentattenuateslipopolysaccharideinduced acute lung injury in rats by activating the phosphoinositide-3-kinase/Akt pathway. Braz J Med Biol Res. 2014 Dec;47(12):10627. doi: 10.1590/1414-431X20143949.

23. Yao W, Luo G, Zhu G, Chi X, Zhang A, Xia Z, Hei Z. Propofol activation of the Nrf2 pathway is associated with amelioration of acute lung injury in a rat liver transplantation model. Oxid Med Cell Longev. 2014;2014:258567. doi: $10.1155 / 2014 / 258567$.

24.Hsing CH, Lin MC, Choi PC, Huang WC, Kai JI, Tsai CC, Cheng YL, Hsieh CY, Wang CY, Chang $\mathrm{YP}$, Chen $\mathrm{YH}$, Chen $\mathrm{CL}$, Lin CF. Anesthetic propofol reduces endotoxic inflammation by inhibiting reactive oxygen species-regulated Akt/IKK $\beta / N F-K B$ signaling. PLoS One. 2011 Mar 8;6(3):e17598. doi: 10.1371/journal. pone.0017598.

25.Gokcinar D, Ergin V, Cumaoglu A, Menevse A, Aricioglu A. Effects of ketamine, propofol, and ketofol on proinflammatory cytokines and markers of oxidative stress in a rat model of endotoxemia-induced acute lung injury. Acta Biochim Pol. 2013;60(3):451-6. PMID: 24020061.

26.Chen HG, Xie KL, Han HZ, Wang WN, Liu DQ, Wang GL, Yu YH. Heme oxygenase-1 mediates the anti-inflammatory effect of molecular hydrogen in LPS-stimulated RAW 264.7 macrophages. Int J Surg. 2013;11(10):10606. doi: 10.1016/j.ijsu.2013.10.007.

27.Wang J, Yang $\mathrm{H}, \mathrm{Hu} \mathrm{X}, \mathrm{Fu}$ W, Xie J, Zhou $X, X u W$, Jiang $H$. Dobutamine-mediated heme oxygenase-1 induction via PI3K and p38 MAPK inhibits high mobility group box 1 protein release and attenuates rat myocardial ischemia/reperfusion injury in vivo. J Surg Res. 2013 Aug;183(2):509-16. doi: 10.1016/j.jss.2013.02.051.

28.Ma L, Wu XY, Zhang LH, Chen WM, Uchiyama A, Mashimo T, Fujino Y. Propofol exerts anti-inflammatory effects in rats with lipopolysaccharide-induced acute lung injury by inhibition of CD14 and TLR4 expression. Braz J Med Biol Res. 2013 Mar;46(3):299-305. doi: 10.1590/1414431X20122379. 
29.Cheng CC, Guan SS, Yang HJ, Chang CC, Luo TY, Chang J, Ho AS. Blocking heme oxygenase-1 by zinc protoporphyrin reduces tumor hypoxia-mediated VEGF release and inhibits tumor angiogenesis as a potential therapeutic agent against colorectal cancer. J Biomed Sci. 2016 Jan 28;23:18. doi: 10.1186/s12929-016-0219-6.

\section{Correspondence:}

Mingsheng Li

Department of Anesthesiology, Tai'an Central

Hospital

Tai'an 271000 Shandong China

Phone: +865386298552

cnmingshengli@126.com

Received: Nov 27, 2017

Review: Jan 26, 2018

Accepted: Feb 28, 2018
Conflict of interest: none

Financial source: none
${ }^{1}$ Research performed at Center Laboratory, Tai'an Central Hospital, Shandong, China. 